\title{
Simultaneous Estimation of Tranexamic Acid and Ethamsylate in Combined Dosage Form by RP-HPLC
}

\section{Prashil Nanotkar*, Prashant Zurao and Avinash Kasture}

Watson Pharmaceuticals, India

\begin{abstract}
A reverse phase high performance liquid chromatographic method has been developed for the simultaneous estimation of tranexamic acid and ethamsylate in tablet formulation. The separation was achieved by Intersil C18 column using a mobile phase of water: acetonitrile: triethylamine $\mathrm{pH} 4(93: 07: 01 \mathrm{v} / \mathrm{v} / \mathrm{v})$. Detection was carried out at $220 \mathrm{~nm}$. Retention time of tranexamic acid and ethamsylate was found to be 2.08 and 4.31 min, respectively. The method has been validated for linearity, accuracy and precision. Linearity for tranexamic acid and ethamsylate were in the range of $100-1000 \mu \mathrm{g} / \mathrm{mL}$ and $10-500 \mu \mathrm{g} / \mathrm{mL}$, respectively. The mean recoveries obtained for tranexamic acid and ethamsylate were in the range of $99.29 \%$ and $99.53 \%$ respectively. Developed method was found to be accurate, precise, selective and rapid for simultaneous estimation of tranexanmic acid and ethamsylate in tablets.
\end{abstract}

Keywords: RP-HPLC; Simultaneous determination; Tranexanic acid; Ethamsylate; Development and validation

\section{Introduction}

Tranexamic acid (TXA) is chemically trans-4-(amino methyl) cyclo hexane carboxylic acid. It is an inhibitor of fibrinolysis and thus has been used as a Haemostatic agent for the treatment of severe hemorrhage. It binds to lysine binding site on plasminogen and prevents its combination with fibrin. It is used in hemophilic patient to prevent hemorrhage and to reduce the need for replacement of blood factors. Several analytical methods have been reported for quantitative determination of tranexamic acid individually by colorimetry and HPLC methods.

Ethamsylate (ETS) is chemically N-ethylamine 2,5-dihydroxybenzenesulphonate. It is a haemostatic agent. It reduces capillary bleeding when platelets are adequate, probably exerts antihyaluronidase action-improves capillary wall stability. It also inhibits $\mathrm{PGI}_{2}$ production and cement abnormal platelet junction but does not stabilize fibrin. It is indicated for prevention and treatment of capillary hemorrhage associated with haematemesis, menorrhagia and post partum hemorrhage. The individual determination of ETS is carried out by UV, HPLC and HPTLC methods. Both the drugs are official in EP and BP.

Fixed dose combination containing TXA and ETS used in menstrual bleeding is recently introduced in the market. Literature survey revealed that no method is yet reported for the estimation of both the drug in combined dosage form. Hence, in the present assay a new simple, sensitive, accurate and specific reverse phase high performance liquid chromatography (RP-HPLC) method is developed and validated for simultaneous estimation of TXA and ETS in tablet formulation.

Working reference standards of TXA and ETS were kindly supplied as gift samples by Indoco remedies, Aurangabad and Smruthi organics Ltd., Solapur, MS. The marketed formulation with brand name Sylate T500 (Emcure, Pune) were procured from the local pharmacy. The solvents used were of HPLC/AR grade. Double distilled water was used for analysis.

\section{Material and Methods}

An isocratic HPLC (JASCO PC 1580), variable wavelength UV- vis (JASCO UV) detector and RP C18 column ( $5 \mu \mathrm{m}$ particle size) was used. Method was developed using C18 $(250 \times 4.6 \mathrm{~mm}, 5 \mu \mathrm{m})$ column. Mobile phase was used for preparation of drug samples throughout the analysis. For preparing the mobile phase water, acetonitrile and triethylamine were mixed together in the ratio of $93: 07: 01 \% \mathrm{v} / \mathrm{v}$ and $\mathrm{pH}$ of resulting solution was adjusted to 4.0. It was filtered before use through $0.45 \mu$ membrane filter. Flow rate employed was $1.0 \mathrm{~mL} / \mathrm{min}$.

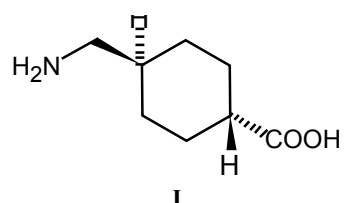

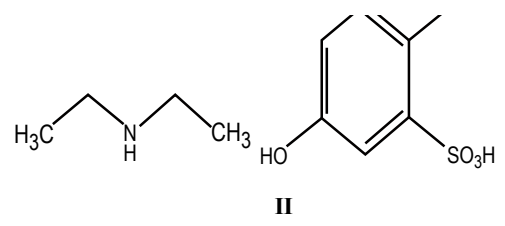

II
Figure 1: Chemical structures: I) Tranexamic acid and II) Ethamsylate.

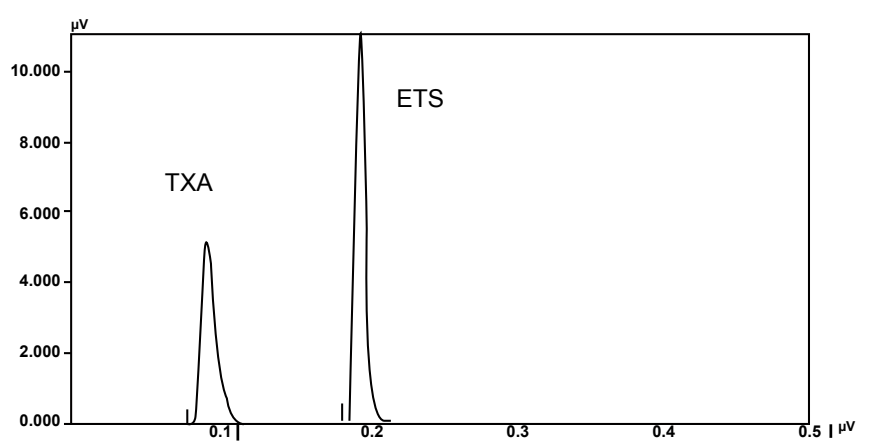

Figure 2: Separation of Tranexamic acid and Ethamsylate in selected mobile phase.

*Corresponding author: Prashil Nanotkar, Officer Bioanalytical operations a Watson Pharmaceuticals, India, E-mail: prashill@yahoo.co.in

Received February 27, 2012; Published August 31, 2012

Citation: Nanotkar P, Zurao P, Kasture A (2012) Simultaneous Estimation of Tranexamic Acid and Ethamsylate in Combined Dosage Form by RP-HPLC. 1: 262. doi:10.4172/scientificreports. 262

Copyright: @ 2012 Nanotkar P, et al. This is an open-access article distributed under the terms of the Creative Commons Attribution License, which permits unrestricted use, distribution, and reproduction in any medium, provided the original author and source are credited. 
Citation: Nanotkar P, Zurao P, Kasture A (2012) Simultaneous Estimation of Tranexamic Acid and Ethamsylate in Combined Dosage Form by RPHPLC. 1: 262. doi:10.4172/scientificreports. 262

Page 2 of 2

Detection was carried out at $220 \mathrm{~nm}$. Among the several mobile phases used for the present assay, water, acetonitrile and triethylamine in the ratio 93: 07: $01 \mathrm{v} / \mathrm{v}, \mathrm{pH} 4.0$ was found to be most suitable. With the above mobile phase a good resolution between TXA and ETS was achieved. UV detection was carried out at $220 \mathrm{~nm}$ as both TXA and ETS showed god absorbance at this wavelength. Standard stock solution of TXA $(1000 \mu \mathrm{g} / \mathrm{mL})$ was prepared by dissolving $100 \mathrm{mg}$ TXA in $100 \mathrm{~mL}$ mobile phase. Standard stock solution of ETS 500 ( $\mu \mathrm{g} /$ $\mathrm{mL}$ ) was prepared by dissolving $50 \mathrm{mg}$ ETS in $100 \mathrm{~mL}$ mobile phase. Aliquots of standard stock solutions of TXA and ETS were taken in $10 \mathrm{~mL}$ volumetric flasks and diluted upto the mark with mobile phase in such a way that final concentrations of TXA and ETS were in the range of $100-1000 \mu \mathrm{g} / \mathrm{mL}$. The standard solutions were further diluted to contain a mixture of $1000 \mu \mathrm{g} / \mathrm{mL}$ of TXA and $500 \mu \mathrm{g} / \mathrm{mL}$ of ETS Twenty tablets of Sylate T500 each containing $500 \mathrm{mg}$ of TXA and $250 \mathrm{mg}$ of ETS were weighed and finely powered separately. Powder equivalent to $500 \mathrm{mg}$ TXA and $250 \mathrm{mg}$ ETS was weighed and dissolved in $100 \mathrm{~mL}$ mobile phase. The solution was sonicated for $15 \mathrm{~min}$ and was filtered through a Whatman filter paper no. 40. Further dilutions were made to get a concentration of $1000 \mu \mathrm{g} / \mathrm{mL}$ of TXA and $250 \mu \mathrm{g} / \mathrm{mL}$ of ETS. These solutions were filtered through $0.45 \mu \mathrm{m}$ membrane filter. Twenty microlitre solution of the each tablet was injected separately and chromatograms were recorded. A representative chromatogram is shown in figure 2 .

\section{Results}

The retention time of TXA and ETS was found to be $2.08 \mathrm{~min}$ and $4.31 \mathrm{~min}$, respectively. The peak shapes of both the drugs were symmetrical and asymmetry factor was less than 2.0. The proposed method was validated as per the standard analytical procedure. Each sample was repeated 6 times and the same retention time was observed in all the cases. Linearity experiments were performed by giving six replicates for both the drugs and response was found to be linear in the range of $80 \%-120 \%$ of the test concentration. Each standard solution $(20 \mu \mathrm{l})$ was injected into the column after filtration using $0.45 \mu \mathrm{m}$ membrane filter. The calibration curves were constructed by plotting the peak areas versus the corresponding drug concentration. The slope and correlation coefficients were determined, which were found to be 0.99995 for TXA and 0.99925 for ETS. In precision studies, the injection repeatability showed a RSD of $0.069 \%$ for tranexamic acid and $0.400 \%$ for ethamsylate. The intra-day analysis showed a RSD of $0.0151 \%$ for tranexamic acid and $0.3468 \%$ for ethamsylate and the inter-day study showed a RSD of 0.5774 for tranexamic acid and 0.3440 for ethamsylate for day 1, 2 and 3, respectively. These results indicate good precision of the samples analyzed. System suitability parameters

\begin{tabular}{|c|c|c|}
\hline Parameter & Tranexamic acid & Ethamsylate \\
\hline Tailing factor & 1.01 & 1.00 \\
\hline Theoretical Plates & 631 & 4952 \\
\hline Capacity factor & 1.08 & 3.28 \\
\hline Resolution & 9.78 & \\
\hline Callibration range & $100-1000$ & $10-100$ \\
\hline
\end{tabular}

Table 1: System suitability parameters.

\begin{tabular}{|c|c|c|c|}
\hline Drug & Amount added $\boldsymbol{\mu g} / \mathbf{m L}$ & Recovery $\%$ & Mean \pm SD \\
\hline Tranexamic acid & 10 & 99.21 & $99.29 \pm 0.0635$ \\
\hline & 20 & 99.29 & \\
\hline Ethamsylate & 05 & 99.55 & $99.53 \pm 0.0826$ \\
\hline & 10 & 99.49 & \\
\hline
\end{tabular}

Table 2: Recovery studies with sample solution. of TXA and ETS are given in the Table 1. Accuracy of the method was calculated by recovery studies $(n=3)$ at five levels. Standard drug solutions containing drugs in the concentration range of $10-20 \mu \mathrm{g} / \mathrm{mL}$ for TXA and $5-10 \mu \mathrm{g} / \mathrm{mL}$ for ETS were added to previously analyzed test solution containing $500 \mu \mathrm{g} / \mathrm{mL}$ TXA and $250 \mu \mathrm{g} / \mathrm{mL}$ ETS. Amount of drug recovered at each level $(n=2)$ was determined. Percent recovery at each level was calculated. The mean\% recovery was found to be $99.29 \%$ for TXA and $99.53 \%$ for ETS. Data from the recovery study are shown in the Table 2. The sample recovery in the marketed formulation was in good agreement with the label claim. High percentage recovery showed that the method was free from interference of excipients used in formulations. The data of result of marketed formulation analysis is shown in the Table 3 . The results of the study indicate that the proposed HPLC method was simple, accurate, precise and selective.

Therefore, the proposed method appears to be suitable for routine analysis of TXA and ETS in their combined dosage form.

\section{Acknowledgements}

The authors are thankful to Smruthi Organics Ltd.,Solapur (M.S.) and Indoco Remedies Ltd., Aurangabad (M.S.), for providing the gift samples of TXA and ETS respectively.

\section{References}

1. British Pharmacopoeia (2007) Vol-I, II, Her Majesty's Stationary Office, London 2083-2084.

2. Council of Europe (2005) European Pharmacopoeia: Published in Accordance with the Convention on the Elaboration of a European Pharmacopoeia, European Treaty Series. Vol-II, (5th edn), 2609.

3. Tripathi KD (2004) Essentials of Medicinal Pharmacology. (5th edn), Jaypee Brothers, Medical Publishers (P) Ltd., New Delhi, 558, 560.

4. Beckett AH, Stenlake JB (2001) Practical Pharmaceutical Chemistry: Part II Fourth Edition. CBS Publisher and Distrubuters New Delhi, 95. 